\title{
Amenorrhea and pituitary human chorionic gonadotrophin production in a 38-year-old presenting as pregnancy of unknown location: case report and review of literature
}

\author{
Theadora Ordog, ${ }^{1}$ Marika Rebecca Raff, MD, ${ }^{1,2}$ Mary B. Rysavy MD, ${ }^{1,2}$ Eyup Hakan \\ Duran, MD, 1,2 James R. Scott, MD, ${ }^{1,2}$ Abey Eapen MBBS., PhD, 1,2
}

Keywords: Amenorrhea, pregnancy of unknown location, methotrexate, pituitary hCG, premature ovarian failure

\begin{abstract}
Background: Amenorrhea and extraplacental production of serum human chorionic gonadotropin (hCG), particularly in young women, can mimic a pregnancy of unknown location. Elevated serum hCG in the absence of pregnancy can pose a diagnostic dilemma and has led to potentially harmful and unwarranted interventions including chemotherapeutic agents like methotrexate or have led to delay in necessary medical interventions in women.
\end{abstract}

We report a case to demonstrate that amenorrhea and extraplacental human chorionic gonadotropin (hCG) production in young women can mimic a pregnancy of unknown location. Furthermore, we performed a critical review of literature on pituitary $h C G$ production.

Case: A 38-year-old woman with a diagnosis of Silver-Russell syndrome, a unicornuate uterus, history of right oophorectomy for a benign serous cystadenoma and a desire for pregnancy presenting with a provisional diagnosis of pregnancy of unknown location.

After performing a thorough review of history, physical examination, ultrasound exams, and a review of hormone analysis [including hCG, Tumor markers, Follicle-stimulating hormone (FSH), Luteinizing hormone (LH), Anti-Mullerian Hormone (AMH), Estradiol (E2) levels], we confirmed the diagnosis of premature ovarian insufficiency and pituitary hCG production.

Conclusions: In women, serum levels of hCG may increase with age, and are not always an indicator of pregnancy. Therefore, it is imperative to interpret false-positive test results and rule out the extraplacental production of hCG. This will help prevent unnecessary surgical procedures and treatment, including chemotherapy.

${ }^{1}$ University of lowa Carver College of Medicine, lowa City, lowa

${ }^{2}$ Department of Obstetrics and Gynecology, University of lowa Health Care, lowa City, lowa

Please cite this paper as: Ordog T, Raff MR, Rysavy MB, Duran EH, Scott JR, Eapen A. Amenorrhea and pituitary human chorionic gonadotrophin production in a 38-year-old presenting as pregnancy of unknown location: case report and review of literature. Proc Obstet Gynecol. 2022;11(1): Article 3 [ 11 p.]. Available from: https://pubs.lib.uiowa.edu Free full text article.

Corresponding author: Abey Eapen MBBS, DRCOG, PhD, Clinical Assistant Professor, Reproductive Endocrinology and Infertility Division, Division, Department of Obstetrics and Gynecology, 200 Hawkins Drive, lowa City, lowa. 52242. Phone: 319-356-4645. Email: abey-eapen@uiowa.edu

Financial Disclosure: The authors report no conflict of interest.

Copyright: (c) 2022 Ordog et al. This is an open-access article distributed under the terms of the Creative Commons Attribution License, which permits unrestricted use, distribution, and reproduction in any medium, provided the original author and source are credited. 


\section{Teaching points}

- Mild elevation in serum hCG levels may be due to pituitary hCG production. This is a benign and physiological condition and may be easily confused with an early pregnancy, particularly in young women.

- Elevated serum hCG in the absence of pregnancy can pose a diagnostic dilemma.

- It is essential to interpret falsepositive test results and rule out the extraplacental production of hCG to prevent unnecessary surgical procedures and treatment, including chemotherapy.

\section{Introduction}

In women of reproductive age, elevated human chorionic gonadotropin ( $\mathrm{hCG}$ ) is typically associated with pregnancy. ${ }^{1}$ In a non-pregnant state, elevated serum hCG may be elevated with advancing female age, gestational trophoblastic disease (GTD), secretion from malignant tumors or pituitary gland, premature ovarian insufficiency, and cross-reactivity during laboratory immunoassay techniques. ${ }^{2-7}$

In pregnancy, hCG is produced by trophoblast cells after implantation and plays an essential role in maintaining the corpus luteum. ${ }^{8}$ Human chorionic gonadotrophin is a glycoprotein and consists of two subunits, the alpha and beta subunits. ${ }^{9}$ Four independent variants of hCG have been identified: hCG, hyperglycosylated hCG, free beta subunit, and pituitary hCG. ${ }^{10-12}$

Pituitary derived hCG has $50 \%$ of the biological activity of placental hCG and is detectable on urine and serum tests. ${ }^{6}$ Pituitary hCG is produced in parallel with structurally similar molecules produced by the anterior pituitary: luteinizing hormone (LH) and folliclestimulating follicle hormone (FSH). ${ }^{13}$ Production and release of these hormones are elevated in women with a history of oophorectomy, perimenopause, and menopause due to the lack of negative feedback on the hypothalamic-ovarian-pituitary axis. Extraplacental secretion of hCG in small amounts occurs in the liver and colon ${ }^{14}$ and in familial hCG syndrome. ${ }^{15}$

Measurements of urine or serum hCG levels are mandatory, before any routine or emergent medical and surgical procedures, even in women of perimenopausal age. The assumption that elevated hCG outside of pregnancy is always pathologic has led to potentially harmful and unwarranted interventions or delaying necessary medical interventions for women. ${ }^{16}$ Therefore, it is imperative to have a conclusive diagnosis to avoid any clinical confusion.

We highlight this case to demonstrate that amenorrhea and extraplacental production of hCG hormone in a woman of reproductive age may present similarly to a pregnancy of unknown location.

\section{Case History}

We obtained written informed consent from this patient for publication of this 
case report. A 38-year-old, gravida 0 was seen in the reproductive endocrinology and infertility (REI) clinic of an Academic ObGyn unit in Oct 2020. She was referred with a provisional diagnosis of pregnancy of unknown location (PUL), refractory to intramuscular (IM) methotrexate treatment.

Her medical history was significant for Silver-Russell Syndrome, which is a disorder characterized by intrauterine growth restriction, postnatal growth abnormalities, and mild developmental delay in some cases. In addition, she had kyphoscoliosis, generalized anxiety disorder, and exercise-induced asthma. She attained menarche at 11 years, has had regular menstrual cycles since, and has never used contraception. She had a history of abnormal pap smear, which was assessed by colposcopy and cervical biopsy in 2002 but did not require treatment. She had normal pap smears since. She was a former smoker. Her height was $1.46 \mathrm{~m}$ and her weight was $42.3 \mathrm{~kg}$ for a BMl of 19.83 $\mathrm{kg} / \mathrm{m}^{2}$.

In May 2019, she presented to her local gynecologist with intermittent pelvic pain, abdominal bloatedness, dysmenorrhea, and intermenstrual bleeding. An endometrial biopsy was performed and an ultrasound at that time confirmed a complex appearing ovarian cyst on the right ovary. She was referred to the tertiary center for further evaluation. Ultrasound confirmed a unicornuate uterus, a $17 \mathrm{~mm}$ intramural myoma, and a complex ovarian cyst measuring $70 \times 59 \mathrm{~mm}$, with low level echoes. Serum tumor markers were normal. After having a negative urine pregnancy test, she underwent a laparoscopy in July 2020 and findings were as follows: The uterus appeared abnormal with a left unicornuate uterus and a right rudimentary horn. The left tube and ovary appeared normal. The right ovary was significantly enlarged with a simple cyst and no normal ovarian tissue visualized; the right tube appeared normal without dilation of the fimbriated end. Additionally, a few implants and powder-burn marks concerning for endometriosis were seen on the right tube, posterior cul-de-sac and on the left pelvic side wall. She underwent a right oophorectomy and an endometrial biopsy with an uneventful recovery. Pathology examination confirmed a benign serous cystadenoma and proliferative endometrium with no evidence of dysplasia or hyperplasia.

Following her surgery, she started attempts at conception. Her last regular menstrual period was in April 2020 but had irregular bleeding since. Home urine pregnancy tests were performed, as she experienced fatigue, hot flashes, and two months amenorrhea. The pregnancy tests revealed a faint line and were read as inconclusive. She presented to her primary care physician and a serum hCG was performed. On 08/20/2020, serum hCG was reported to be $12 \mathrm{IU} / \mathrm{L}$. Five weeks later, she was referred to an outpatient gynecology clinic at the tertiary hospital for a confirmation of pregnancy visit. Ultrasound at that time revealed no intrauterine sac or ectopic pregnancy. Endometrium measured $2.7 \mathrm{~mm}$ with normal appearing left ovary. On $09 / 24 / 2020$ a serum hCG was performed and reported at $10 \mathrm{IU} / \mathrm{L}$. She 
denied pelvic pain, vaginal bleeding, nausea, vomiting, fever, or chills but had some abdominal bloating. A diagnosis of pregnancy of unknown location was made and she received the first dose of methotrexate, with her local gynecologist because she lived nearly 2 hours from the tertiary gynecology clinic. Serum hCG the following day was 12 $\mathrm{IU} / \mathrm{L}, 13 \mathrm{IU} / \mathrm{L}$ four days later and $11 \mathrm{IU} / \mathrm{L}$ seven days later. She then received a second dose of IM methotrexate with her local gynecologist, but hCG levels remained elevated at 11 IU/L. Therefore, she came back to the tertiary gynecology clinic for further follow up.

The patient was counselled that she might require a diagnostic laparoscopy or a dilation and curettage to find the location of what was thought to be a pregnancy of unknown location. However, additional labs were also ordered at this visit, which showed an elevated FSH and LH level and a very low AMH levels. Therefore, the patient was referred to REI clinic for further management.

On 08/20, 09/25, 09/28 and 10/01 hCG assay was done in a local lab using an ARCHITECT total beta hCG (Abbott Diagnostics). This technique uses an automated 1:15 dilution protocol. This test has an analytical sensitivity of $\leq 1.2 \mathrm{mlU} / \mathrm{mL}$, with a less than $10 \%$ cross reactivity with $\mathrm{FSH}, \mathrm{LH}$ and TSH. On 09/24 and 10/14 - hCG assay was done in a lab using electrochemiluminescence immunoassay (Cobas). This technique uses an automated if the levels are above $100 \mathrm{mIU} / \mathrm{mL}$. This test has a lower detection limit of $0.500 \mathrm{mlU} / \mathrm{mL}$, with a less than $0.29 \%$ cross reactivity with LH. To rule out the possibility of heterophile antibodies, we performed urine pregnancy tests, which were negative. In addition, serum hCG levels done at both local and the laboratory at our tertiary hospital with different assays rules out the possibility of a laboratory error.

\section{Results}

A comprehensive history and review of systems were performed, and biochemical investigations were initiated. The timeline and results of the test are shown in Table 1. The history of amenorrhea, low serum hCG levels (refractory to 2 doses of methotrexate), history of oophorectomy, low ovarian reserve, symptoms of hot flashes, negative review of other systems, and ultrasound findings did not fit in the diagnosis of a pregnancy or GTD. Therefore, we considered a provisional diagnosis of extraplacental hCG production.

We discussed the implications of the diagnosis and discussed management options, including oral contraceptive pills or $\mathrm{GnRH}$ analogs. She preferred not to initiate either of these treatment options after a discussion that there are no health risks associated with persistent low hCG levels.

Pituitary hCG production in the setting of premature ovarian insufficiency was further confirmed after review of biochemical parameters, as listed in Table 1. 
TABLE 1. Summary of test results.

\begin{tabular}{|l|c|c|c|c|c|c|c|c|c|c|}
\hline Date & hCG & AMH & FSH & LH & E2 & PRL & TSH & Ca 19-9 & CEA & Ca-125 \\
\hline $06 / 17 / 2019$ & & & & & & & 1.37 & $<1$ & 1.7 & 18 \\
\hline $08 / 20 / 2020$ & 12 & & & & & & & & & \\
\hline $09 / 24 / 2020$ & 10 & & & & & & & & & \\
\hline $09 / 25 / 2020$ & 12 & & & & & & & & & \\
\hline $09 / 28 / 2020$ & 13 & & & & & & & & & \\
\hline $10 / 01 / 2020$ & 11 & & & & & & & & & \\
\hline $10 / 14 / 2020$ & 14 & $<0.03$ & 179.7 & 142.7 & & 6.7 & 2.07 & & & \\
\hline $10 / 30 / 2020$ & & & 108 & 107.5 & 71 & & & & & \\
\hline
\end{tabular}

Note: $\mathrm{hCG}=$ human chorionic gonadotrophin, $\mathrm{AMH}=$ antimullerian hormone, $\mathrm{FSH}=$ follicle stimulating hormone, $\mathrm{LH}=$ luteinizing hormone, $\mathrm{E} 2=$ estradiol, $\mathrm{PRL}=$ prolactin, $\mathrm{TSH}=$ thyroid stimulating hormone,

Laboratory reference ranges: hCG (non-pregnant) $<3 \mathrm{IU} / \mathrm{L}$ (post-menopausal) $<3-8 \mathrm{IU} / \mathrm{L}$, AMH 0.147-7.49 ng/ml, FSH (postmenopausal) $25.8-134.8 \mathrm{mIU} / \mathrm{mL}, \mathrm{LH}$ (postmenopausal) $7.7-58.5 \mathrm{mIU} / \mathrm{mL}$, Estradiol (postmenopausal) $<5-138 \mathrm{pg} / \mathrm{mL}$, Prolactin 4.8-23.3 ng/mL, TSH 0.27-4.2 $\mu \mathrm{IU} / \mathrm{mL}$, Ca 19-9 <34 U/mL, CEA 0.0-5.4 ng/mL, CA-125 $<34 \mathrm{u} / \mathrm{mL}$

\section{Discussion}

The trends in the rise and decline of serum hCG in early pregnancy are useful in diagnosing early pregnancy and related complications. As an example, serial hCG measurements and advancement in transvaginal ultrasonography have reduced the mortality rate of ectopic pregnancy. ${ }^{17}$ However, there are clinical scenarios that may lead to detectable serum hCG levels which are not related to pregnancy.

Several studies have evaluated these scenarios and may occur in gestational trophoblastic disease, germ cell tumors, gastrointestinal malignancies, pituitary production, heterophile antibody interference, and undifferentiated malignancies. ${ }^{2-7}$ Furthermore, falsely elevated serum hCG levels have been described due to artifactual errors ${ }^{7}$, rheumatoid factor ${ }^{12}$, IgA deficiency ${ }^{18}$, chronic renal failure ${ }^{19}$, red blood cell transfusion ${ }^{19}$, and exogenous hCG abuse. $^{20}$ Insufficient knowledge on various causes of non-pathological elevation of serum hCG in a nonpregnant state may result in delay or cancellation of necessary medical treatments as well as harmful interventions including hysterectomy and chemotherapy. ${ }^{13,21}$

Pituitary hCG production occurs alongside structurally similar hormones, $\mathrm{FSH}$ and $\mathrm{LH}$. The alpha subunit of hCG is identical to $\mathrm{FSH}, \mathrm{LH}$, and $\mathrm{TSH}$; their 
respective beta subunits determine differences in these hormones' biological activity. ${ }^{13}$ hCG of pituitary origin has $50 \%$ of the biological activity in vitro as $\mathrm{hCG}$ purified from the urine of pregnant women. ${ }^{22}$ The gonadotropinreleasing hormone stimulates the release of $\mathrm{hCG}$, along with other pituitary hormones. Pituitary hCG production increases in the perimenopausal and menopausal state. The exact mechanism for pituitary hCG production remains unknown; however, it may be likely due to peri- and postmenopausal increase in $\mathrm{GnRH}$ and reduced ovarian negative feedback mechanism on GnRH secretion. ${ }^{23}$ Pituitary hCG production has been demonstrated by a $\mathrm{GnRH}$ stimulation test followed by petrosal sinus sampling and with biopsy of the pituitary gland. ${ }^{24}$

The presence of hCG in pituitary adenomas was investigated in a study consisting of 123 patients undergoing surgery for pituitary adenomas. ${ }^{25}$ In this retrospective analysis, the authors quantitatively investigated the immunohistochemical expression of hCG and explored the relation to the endocrine profile, tumor recurrence, and Ki-67 nuclear labeling. A total of 123 histopathology records were analyzed, which included 62 males. The average age (in years) was 55+/- 15 (range: 16 82 years). Ninety-three $(76 \%)$ tumors were primary, and $30(24 \%)$ tumors were recurrent adenomas. Immunohistochemically, 107 (87\%) of pituitary adenomas expressed $\beta$-hCG, more common in non-functioning pituitary adenoma.

To establish reference ranges for hCG in postmenopausal women, the authors performed a retrospective analysis of serum samples from 798 women over 55 years. ${ }^{26}$ Further, they subgrouped them into three groups, based on advancing age. Analysis of FSH and hCG were performed. A serum hCG level over $5 \mathrm{IU} / \mathrm{L}$ was identified in $8 \%$ of women over 55 years. The hCG or FSH concentration did not increase with age, and this study recommended a cut off of $14 \mathrm{IU} / \mathrm{L}$ for women over 55 years. In a retrospective analysis of 39,742 serum quantitative hCG tests from seven testing centers, the same group authors identified the negative predictive value of $\mathrm{FSH}$ to rule out pregnancy and placental hCG production. They incorporated a reflex FSH testing along with serum hCG values and proposed an algorithm. The authors demonstrated that a serum FSH level less than 45.0 IU/L identified hCG of placental origin with $100 \%$ sensitivity and $75 \%$ specificity and concluded that a pregnancy is unlikely in a perimenopausal woman with hCG between 5 and 14 with $\mathrm{FSH}>20 \mathrm{IU} / \mathrm{mL}$.

Several studies evaluating the pituitary origin of persistently elevated hCG have shown serum hCG ranging from 5-39 IU/L (23-26). A case report demonstrated an unusually high hCG level (over $40 \mathrm{IU} / \mathrm{L}$ ) in a 53-year-old postmenopausal woman, ultimately confirmed pituitary origin after estrogenprogesterone hormone replacement therapy. ${ }^{23}$ The additional endocrine assessment confirmed FSH of $66 \mathrm{IU} / \mathrm{L}$, $\mathrm{LH}$ of $38 \mathrm{IU} / \mathrm{l}$, and TSH of $1.5 \mathrm{lU} / \mathrm{L}$. The authors of another case report investigated a high hCG result of 136 $\mathrm{IU} / \mathrm{L}$ in a 43-year-old, woman who was not sexually active..$^{27}$ She had a medical history of acquired thrombotic 
thrombocytopenic purpura (TTP) and received therapeutic plasma exchange (TPE). Extensive investigation protocols were initiated to rule out potential causes of non-pregnancy related endogenous hCG production, including pituitary hCG - all of which was reported to be negative. Finally, the discrepancy of elevated hCG, in this case, was discovered by retrospective measurement of hCG levels in a preTPE, remnant sample. It is interesting to note that applying the algorithm from Gronowski et al. ${ }^{26}$ to both case reports highlights the negative predictive value of $\mathrm{FSH}$, and therefore, maybe a useful clinical tool.

The management options include the use of combined oral contraceptive pills, estrogen-progesterone therapy or high estrogen - birth control pills for 3 to 4 weeks, or even no treatment. ${ }^{13,23,28}$ This has a diagnostic and therapeutic value, and these therapies may be used as long-term therapy to reduce pituitary hCG levels by exerting negative feedback. There are no known adverse effects of chronic low-level elevation in hCG other than iatrogenic interventions. ${ }^{13}$

In a prospective analysis of outcomes of 36 cases of peri- and postmenopausal hCG elevation, the authors highlighted the false assumptions of malignancy, delay in critical and elective surgical and medical procedures, use of expensive, invasive testing, use of unwarranted chemotherapy, and associated stress in these women. ${ }^{13}$ Further, the authors emphasized the normalcy of persistent, low-level elevation in hCG in these age groups and presented a pathway for investigation.
In non-pregnant women, the differential diagnosis for persistently low positive serum hCG level or 'phantom hCG' should include non-malignant conditions like heterophile antibody, pituitary hCG production, exogenous hCG supplementation, and Munchausen's syndrome. The differential diagnosis for pre-malignant and malignant conditions includes active gestational trophoblastic disease, quiescent gestational trophoblastic disease, and nontrophoblastic malignancy. ${ }^{29}$ The case that we report is unique in view of a medical diagnosis of Silver-Russel syndrome and added more complexity for a diagnosis of pituitary hCG production in view of a uterine anomaly, and unanticipated diagnosis of ovarian insufficiency.

The 38-year-old female in our case report, had steady hCG levels that were demonstrated over several months. She is a nullipara with no previous history of pregnancy or GTD. Given her previous history of regular menses, the initial medical provider considered a pregnancy of unknown location, and the patient underwent two rounds of methotrexate therapy. However, with the relatively recent onset of amenorrhea, low AMH level, persistently elevated hCG levels after two doses of IM methotrexate, negative constitutional symptoms, and examination findings, elevated $\mathrm{FSH}$, elevated $\mathrm{LH}$, low estradiol levels, and normal transvaginal ultrasound examination - the most likely diagnosis is of pituitary hCG production. The persistent low serum hCG levels in this case scenario are not consistent with heterophile antibody levels which are usually in the range of $25-30 \mathrm{IU} / \mathrm{L}$. 
Procreative management options with in-vitro fertilization (IVF) treatment utilizing donor oocytes, donor embryos, and adoption were discussed, and the couple decided to proceed with IVF treatment using donor oocytes. We plan to initiate a mock endometrial preparation cycle in preparation for embryo transfer. While suppressing the pituitary hCG production, the estrogenprogesterone hormone therapy will also enable us to perform an endometrial thickness evaluation before her assisted reproductive technology (ART) treatment, thus offering diagnostic and therapeutic value.

\section{Conclusion}

Pituitary hCG production is a benign, physiologic cause for a persistent low elevated level of hCG. This may be associated with increasing maternal age and peri- and postmenopausal states. Elevated serum hCG in the absence of pregnancy can pose a diagnostic dilemma. Therefore, it is essential to consider it in the differential diagnosis and perform a comprehensive review of history, appropriate interpretation of results, and understand different causes. This will aid clinicians in a timely and accurate diagnosis to avoid potentially harmful treatments.

\section{Authors contributions}

$M R R$, and $A E$ collated the clinical information and TO wrote the first draft of the manuscript. $M R, M R R$ and $A E$ were involved in clinical care. $M R, E H D$, and JS performed a critical review of the manuscript. $A E$ is the corresponding author.

\section{References}

1. Mishell DR Jr, Thorneycroft IH, Nagata Y, Murata T, Nakamura RM. Serum gonadotropin and steroid patterns in early human gestation. Am J Obstet Gynecol. 1973 Nov 1;117(5):631-42. https://doi.org/10.1016/00029378(73)90205-6. PMID: 4742372.

2. Snyder JA, Haymond S, Parvin CA, Gronowski AM, Grenache DG. Diagnostic considerations in the measurement of human chorionic gonadotropin in aging women. Clin Chem. 2005 Oct;51(10):1830-5. https://doi.org/10.1373/clinchem.2005.0 53595. Epub 2005 Aug 11. PMID: 16099935.

3. Cole LA, Shahabi S, Butler SA, Mitchell $H$, Newlands ES, Behrman HR, Verrill HL. Utility of commonly used commercial human chorionic gonadotropin immunoassays in the diagnosis and management of trophoblastic diseases. Clin Chem. 2001 Feb;47(2):308-15.

https://doi.org/10.1093/clinchem/47.2.30 8. PMID: 11159780.

4. Marcillac I, Troalen F, Bidart JM, Ghillani P, Ribrag V, Escudier B, Malassagne B, Droz JP, Lhommé $C$, Rougier $\mathrm{P}$, Duvillard $\mathrm{P}$, Prade $\mathrm{M}$, Lugagne PM, Richard F, Poynard T, Bohuon C, Wands J, Bellet D. Free human chorionic gonadotropin beta subunit in gonadal and nongonadal neoplasms. Cancer Res. 1992 Jul 15;52(14):3901-7. PMID: 1377600. https://cancerres.aacrjournals.org/conte nt/52/14/3901.long 
5. Stenman UH, Alfthan $\mathrm{H}$, Ranta $\mathrm{T}$, Vartiainen E, Jalkanen J, Seppälä M. Serum levels of human chorionic gonadotropin in nonpregnant women and men are modulated by gonadotropin-releasing hormone and sex steroids. J Clin Endocrinol Metab. $1987 \quad$ Apr;64(4):730-6. https://doi.org/10.1210/icem-64-4-730. oi: PMID: 3546353.

6. Birken S, Maydelman $Y$, Gawinowicz MA, Pound A, Liu Y, Hartree AS. Isolation and characterization of human pituitary chorionic gonadotropin. Endocrinology. 1996 Apr;137(4):140211.

https://doi.org/10.1210/endo.137.4.8625 917. PMID: 8625917.

7. Kricka LJ. Human anti-animal antibody interferences in immunological assays. Clin Chem. 1999 Jul;45(7):942-56. Erratum in: Clin Chem 2000 Oct;46(10):1722.

https://doi.org/10.1093/clinchem/45.7.94 2. PMID: 10388468.

8. Rao CV, Griffin LP, Carman FR Jr. Prostaglandin F2alpha binding sites in human corpora lutea. J Clin Endocrinol Metab. $1977 \quad$ Jun;44(6):1032-7. https://doi.org/10.1210/jcem-44-6-1032. PMID: 406267.

9. Montagnana $\mathrm{M}$, Trenti $\mathrm{T}$, Aloe $\mathrm{R}$, Cervellin G, Lippi G. Human chorionic gonadotropin in pregnancy diagnostics. Clin Chim Acta. 2011 Aug 17;412(1718):1515-20.

https://doi.org/10.1016/i.cca.2011.05.02 5. Epub 2011 May 25. PMID: 21635878.

10. Kovalevskaya G, Genbacev O, Fisher SJ, Caceres E, O'Connor JF. Trophoblast origin of hCG isoforms: cytotrophoblasts are the primary source of choriocarcinoma-like hCG. Mol Cell Endocrinol. 2002 Aug 30;194(1-2):14755. https://doi.org/10.1016/S03037207(02)00135-1. PMID: 12242037.
11. Sasaki Y, Ladner DG, Cole LA. Hyperglycosylated human chorionic gonadotropin and the source of pregnancy failures. Fertil Steril. 2008 Jun;89(6):1781-6.

https://doi.org/10.1016/j.fertnstert.2007. 03.010. Epub 2007 Aug 6. PMID: 17675003.

12. Cole LA. Biological functions of hCG and hCG-related molecules. Reprod Biol Endocrinol. 2010 Aug 24;8:102. https://doi.org/10.1186/1477-7827-8-

102. PMID: 20735820; PMCID: PMC2936313.

13. Cole LA, Khanlian SA, Muller CY. Detection of perimenopause or postmenopause human chorionic gonadotropin: an unnecessary source of alarm. Am J Obstet Gynecol. 2008 Mar;198(3):275.e1-7.

https://doi.org/10.1016/j.ajog.2007.09.03 4. PMID: 18313448.

14. Alfthan $H$, Haglund $C$, Roberts $P$, Stenman UH. Elevation of free beta subunit of human choriogonadotropin and core beta fragment of human choriogonadotropin in the serum and urine of patients with malignant pancreatic and biliary disease. Cancer Res. 1992 Sep 1;52(17):4628-33. PMID: 1324787.

https://cancerres.aacrjournals.org/conte nt/52/17/4628.long

15. Tan A, Van der Merwe AM, Low $X$, Chrystal K. Familial HCG syndrome: A diagnostic challenge. Gynecol Oncol Rep. 2014 Jun 1;10:47-8. https://doi.org/10.1016/i.gynor.2014.05.0 05. PMID: 26082938; PMCID: PMC4458743.

16. Cole LA, Khanlian SA. Inappropriate management of women with persistent low hCG results. J Reprod Med. 2004 Jun;49(6):423-32. PMID: 15283048. 
17. Delabaere A, Huchon C, Lavoue V, Lejeune V, Iraola E, Nedellec S, Gallot V, Capmas P, Beucher G, Subtil D, Carcopino X, Vialard F, Nizard J, Quibel $\mathrm{T}$, Costedoat-Chalumeau N, Legendre G, Venditelli F, Rozenberg P, Lemery D, Deffieux $X$. Standardisation de la terminologie des pertes de grossesse: consensus d'experts du Collège national des gynécologues et obstétriciens français (CNGOF) [Definition of pregnancy losses: Standardization of terminology from the French National College of Obstetricians and Gynecologists (CNGOF)]. J Gynecol Obstet Biol Reprod (Paris). 2014 Dec;43(10):756-63. French. https://doi.org/10.1016/i.jgyn.2014.09.01 0. Epub 2014 Nov 6. PMID: 25447359.

18. Knight AK, Bingemann $T$, Cole L, Cunningham-Rundles $C$. Frequent false positive beta human chorionic gonadotropin tests in immunoglobulin A deficiency. Clin Exp Immunol. 2005 Aug;141(2):333-7. https://doi.org/10.1111/j.13652249.2005.02837.x. PMID: 15996198; PMCID: PMC1809437.

19. Fahy BG, Gouzd VA, Atallah JN. Pregnancy tests with end-stage renal disease. J Clin Anesth. 2008 Dec;20(8):609-13.

https://doi.org/10.1016/j.jclinane.2008.0 5.025. PMID: 19100935.

20. Delbeke FT, Van Eenoo P, De Backer $P$. Detection of human chorionic gonadotrophin misuse in sports. Int $\mathrm{J}$ Sports Med. 1998 May;19(4):287-90. https://doi.org/10.1055/s-2007-971920. PMID: 9657371.

21. Cole LA, Rinne KM, Shahabi S, Omrani A. False-positive hCG assay results leading to unnecessary surgery and chemotherapy and needless occurrences of diabetes and coma. Clin Chem. 1999 Feb;45(2):313-4. https://doi.org/10.1093/clinchem/45.2.31 3. PMID: 9931066.
22. Birken $S$, Maydelman $Y$, Gawinowicz MA, Pound A, Liu Y, Hartree AS. Isolation and characterization of human pituitary chorionic gonadotropin. Endocrinology. 1996 Apr;137(4):140211.

https://doi.org/10.1210/endo.137.4.8625 917. PMID: 8625917.

23. Demir AY, Musson RE, Schöls WA, Duk JM. Pregnancy, malignancy or mother nature? Persistence of high hCG levels in a perimenopausal woman. BMJ Case Rep. 2019 Jan 3;12(1):e227203. https://doi.org/10.1136/bcr-2018227203. PMID: 30610037; PMCID: PMC6326279.

24. Patton PE, Hess DL, Cook DM, Loriaux DL, Braunstein GD. Human chorionic gonadotropin production by the pituitary gland in a premenopausal woman. Am J Obstet Gynecol. 1998 Jun;178(6):1138$42 . \quad$ https://doi.org/10.1016/S00029378(98)70345-X. PMID: 9662292.

25. Doyle PM, Thiryayi WA, Joshi A, du Plessis D, Kearney T, Gnanalingham KK. Beta human chorionic gonadotropin (beta-hCG) expression in pituitary adenomas: relationship to endocrine function and tumour recurrence. Pituitary. 2009;12(3):190-5. https://doi.org/10.1007/s11102-0080155-x. PMID: 19005764.

26. Gronowski AM, Fantz CR, Parvin CA, Sokoll LJ, Wiley CL, Wener $\mathrm{MH}$, Grenache DG. Use of serum FSH to identify perimenopausal women with pituitary hCG. Clin Chem. 2008 Apr;54(4):652-6.

https://doi.org/10.1373/clinchem.2007.1 00305. Epub 2008 Feb 7. PMID: 18258666.

27. Johnson LM, Gniadek TJ, Cohn CS, Bachowski G, Karger AB. A 43-year-old woman with unexplained elevation of hCG. Clin Biochem. 2018 May;55:86-88. https://doi.org/10.1016/j.clinbiochem.201 8.03.016. Epub 2018 Mar 26. PMID: 29588177. 
28. Schmid BC, Reilly A, Oehler MK. Management of nonpregnant women with elevated human chorionic gonadotropin. Case Rep Obstet Gynecol. 2013;2013:580709. https://doi.org/10.1155/2013/580709.

Epub 2013 Oct 23. PMID: 24251053; PMCID: PMC3819893.

29. Oyatogun O, Sandhu M, Barata-Kirby S, Tuller E, Schust DJ. A rational diagnostic approach to the "phantom hCG" and other clinical scenarios in which a patient is thought to be pregnant but is not. Ther Adv Reprod Health. 2021 Jun 13;15:26334941211016412.

https://doi.org/10.1177/2633494121101

6412. PMID: 34179786; PMCID:

PMC8207263. 